\title{
Neuroprotective effects of isoflurane against lipopolysaccharide- induced neuroinflammation in BV2 microglial cells by regulating HMGB1/TLRs pathway
}

\author{
Degang Han, Zheng Zhou, Jingpeng Liu, Tingting Wang, Jinbo Yin \\ Department of Neurosurgery, XInqiao Hospital, Army Medical University, China
}

\begin{abstract}
Microglia, as the first line of defence of the central nervous system (CNS), has a major role in inflammatory response. It was reported that isoflurane has a neuroprotective role in the pathological process of CNS by interfering with inflammatory response. While the mechanism and function of isoflurane in microglia-mediated inflammation are still not clearly articulated. In our study, the inflammation model was established by the activation of lipopolysaccharide (LPS) in BV2 cells in vitro. The results demonstrated that isoflurane inhibited the release of nitric oxide (NO) and enhanced the survival of BV2 cells, meanwhile, isoflurane reduced the levels of inflammatory factors and downregulated the expressions of inflammation-related genes and proteins in LPS-mediated BV2 cells. Furthermore, we demonstrated that overexpression of high-mobility group box 1 protein (HMGB1) could reverse the reduction in NO concentration, enhancement of cell BV2 viability and inhibition of inflammatory response, which were mediated by isoflurane in LPS-induced BV2 cells. Therefore, we suggested that isoflurane inhibits the activation of LPS-induced neuro microglia and reduces the release of inflammatory factors by regulating HMGB1, suggesting that isoflurane might play a protective role in LPS-induced neuroinflammation through the HMGB1 pathway.
\end{abstract}

Key words: neuroprotective, lipopolysaccharide, isoflurane, high-mobility group box 1 protein, microglia cells.

\section{Introduction}

Microglia are the immune effector cells of the central nervous system (CNS) after activation [15]. Microglia are involved in brain diseases such as brain injury, inflammation, multiple sclerosis, Alzheimer's disease and recurrent seizures [3,7]. Appropriate inhibition of microglial cell activation at the early stage can reduce the pathological damages caused by its activation. Therefore, understanding the molecular mechanism of microglial cell activa- tion is conducive to formulating effective therapeutic strategies.

Isoflurane, as one of the representative drugs of inhaled anaesthetics, is widely used in clinical anaesthesia due to its good anaesthetic effect, ease of adjusting the anaesthetic depth, light effect on circulation, low toxicity, and rapid induction and recovery $[2,27]$. Isoflurane can prevent $\mathrm{N}$-methyl-D-aspartic acid (NMDA) receptors and activate $\gamma$-amino butyric acid (GABA) receptors to cause nerve cell depolarization and $\mathrm{Ca}^{2+}$ influx, which promotes activation of

\section{Communicating author}

Jinbo Yin, Xinqiao Hospital, Army Medical University, No. 83, Xinqiao Street, Shapingba district, Chongqing 400037, China,

e-mail: yinjinbo_doc@aliyun.com 
caspase-3 and causes neuronal toxicity [18]. Studies have demonstrated that isoflurane pretreatment can relieve neuron damage by increasing $\mathrm{M} 2$ microglia cells and reducing inflammatory factors in brain tissues [14,31,37]. More and more studies have also demonstrated that isoflurane has a definite neuroprotective effect in vivo and in vitro $[23,32]$. Isoflurane has therapeutic significance in some diseases related to nerve damage (such as cerebral ischemia, hypoxia, brain injury, etc.) $[12,40]$. Therefore, isoflurane post-treatment therapy is expected to become one of the treatment strategies of CNS disorders. Further studies on the neuroprotective mechanism of isoflurane will provide a new idea for the clinical treatment of CNS disorders.

Recently, it has been found that the combined application of isoflurane under different brain metabolic conditions had no significant effect on glutamic acid and NMDA receptor-mediated calcium influx [28]. It was suggested that the decrease in the cerebral metabolic rate is only one of the mechanisms of the neuroprotective effect of inhaled anaesthetics. At present, the pathophysiological processes of CNS disorders include excitatory amino acid poisoning, oxidative stress, intracellular calcium overload and apoptosis [4,17]. However, experimental or clinical treatment for the above mechanisms cannot completely control the pathological progress of CNS disorders. That suggests that there may be other mechanisms involved in the occurrence and development of CNS disorders. In recent years, it has been pointed out that the mechanism of immune inflammation has a vital contribution to the pathological mechanism of CNS disorders [11,35].

A wide array of studies have verified that isoflurane has a neuroprotective effect by inhibiting the immune inflammatory response $[1,8,39]$. In particular, among many inflammatory-related factors, high mobility group proteins (HMG, high mobility group protein) play an important role in nervous system diseases [29]. The HMG protein family can widely participate in a variety of crucial nuclear biological functions, including DNA replication, transcription, recombination and repair, etc. [30]. According to its structure, HMG protein can be divided into $\mathrm{HMGB}$, HMGA and HMGN [36]. Among them, HMGB1 is the most abundant protein in the HMG family. Intranuclear HMGB1 can facilitate DNA replication and gene transcription [16]. Extracellular HMGB1, as an inflammatory mediator, can activate macrophages, monocytes and endothelial cells, release inflammatory cytokines, such as interleukin (IL)-1 $\beta$, IL-6, IL-8 and tumour necrosis factor $\alpha$ (TNF- $\alpha$ ), and further stimulate and maintain inflammatory response [26]. In addition, HMGB1 receptors, such as receptor for advanced glycation end products (RAGE), Toll-like receptor (TLR) 4, TLR2, can mediate HMGB1 to participate in the immune response [34]. However, isoflurane plays a neuroprotective role in the pathological process of CNS disorders through HMGB1 and its extremely related receptor pathway is rarely reported. We hypothesized that isoflurane post-treatment may play a neuroprotective role in the pathological process of CNS disorders by inhibiting HMGB1 and its receptor (RAGE, TLR2, TLR4) pathway.

In our study, microglia cells were used as an experimental model to explore whether the neuroprotective effect of isoflurane is in connection with the HMGB1 pathway.

\section{Material and methods \\ Cell culture and study design}

Mouse microglia cells (BV2 cells) were purchased from Cell Center, Institute of Basic Medicine, Chinese Academy of Medical Sciences. Briefly, the BV2 cells were cultured in Dulbecco's modified Eagle's medium (DMEM, Thermo Fisher Scientific, Waltham, MA, USA) supplied with $10 \%$ foetal bovine serum (FBS, Thermo Fisher Scientific, Waltham, MA, USA), 100 units/ml penicillin, and $100 \mu \mathrm{g} / \mathrm{ml}$ streptomycin (Thermo Fisher Scientific, Waltham, MA, USA) at $37^{\circ} \mathrm{C}$ with $5 \% \mathrm{CO}_{2}$. The complete DMEM medium was changed once a day and cells passed it every 3 days. When the cells confluenced to about $80 \%$, BV2 cells were treated with $0.1 \mu \mathrm{g} / \mathrm{ml}, 1 \mu \mathrm{g} / \mathrm{ml}$ and $10 \mu \mathrm{g} / \mathrm{ml}$ LPS (Sigma, St. Louis, MO) for $4 \mathrm{hrs}$, the BV2 cells were also treated with $0.1 \mu \mathrm{g} / \mathrm{ml}, 1 \mu \mathrm{g} / \mathrm{ml}$ and $2 \mu \mathrm{g} / \mathrm{ml}$ isoflurane (Invitrogen, China) for $24 \mathrm{hrs}$. The concentration of isoflurane was determined based on previous literature reports $[39,41]$.

\section{Plasmid construction and transfection}

Firstly, the BV2 cell inflammatory model was established by selecting an appropriate concentration of LPS, and was treated with an appropriate isoflurane concentration that have a significant protective effect on cells. Secondly, an HMGB1 overexpression plasmid and pcDNA3.1-HMGB1 were commercially constructed by GenePharma (Shang- 
hai, China), and empty pcDNA 3.1 vector (NC) was used as a control group. To establish cell lines with transient overexpression of HMGB1 and BV2 cells $\left(2 \times 10^{5}\right.$ cells/well) were seeded in a 6 -well plate and incubated for $12 \mathrm{hrs}$ at $37^{\circ} \mathrm{C}$. And then the cells were transfected with $10 \mu \mathrm{g}$ pcDNA3.1-HMGB1 plasmid or control pcDNA3.1 vector using the Lipofectamine 3000 reagent (Invitrogen; Thermo Fisher Scientific, Inc., Waltham, MA, USA) according to the manufacturer's protocol. Forty-eight hrs after transfection, BV2 model cells were treated with isoflurane in fresh medium and incubated for $24 \mathrm{hrs}\left(\right.$ at $37^{\circ} \mathrm{C}, 5 \% \mathrm{CO}_{2}$ ), after which the samples were subjected to analysis.

\section{MTT assay}

BV2 cells were inoculated into 96 -well plate at a density of $1 \times 10^{4} / \mathrm{ml}$ and then randomly divided into different groups in different experiments. The cells in the control group were cultured normally and isoflurane was added $1 \mathrm{~h}$ after LPS. After incubation for $24 \mathrm{hrs}$ at $37^{\circ} \mathrm{C}$, cells from each well were added with $10 \mu \mathrm{l}$ MTT solution ( $5 \mathrm{mg} / \mathrm{ml}$; Sigma, USA, Cat. no. M-2128), respectively. The medium was supplemented to $100 \mu \mathrm{l}$ incubated for $4 \mathrm{hrs}$, then the culture medium was sucked out. The absorbance OD (570) was measured by adding $150 \mu \mathrm{l}$ DMSO to each well. The formula of the cell survival rate was as follows: cell survival rate $(\%)=$ [experimental group OD (570)-zero adjustment group OD (570)] / [control group OD (570)-zero adjustment group OD (570)] $\times 100 \%$.

\section{Griess}

BV2 cells were inoculated at a density of $1 \times$ $10^{5}$ cells $/ \mathrm{ml}$ on 24 -well plates. After the cells were adhered to the wall, the cells were treated with different concentrations of LPS $(0.1,1.0$ and $10.0 \mu \mathrm{g} / \mathrm{ml})$. BV2 cells were stimulated by LPS for $24 \mathrm{hrs}$. According to the standard of $50 \mu \mathrm{l}$ per well, the cell serum and standard of each group were added to the enzyme standard plate, and then $50 \mu \mathrm{l}$ of Griess Reagent I and $50 \mu \mathrm{l}$ of Griess Reagent II were added to each well. Then absorbance OD (540) was measured. The content of NO in the sample was determined according to the standard curve.

\section{Real time reverse transcription polymerase chain reactions (RT-qPCR) assay}

Total RNA was extracted with an RNA extraction kit (Fastagen, Shanghai, China) according to the manufacturer's protocol. The isolated RNA was reversely transcribed into CDNA using PrimeScript ${ }^{\text {TM }}$ RT Master Mix (TaKaRa, Dalian, China). The RT-qPCR assay was performed using synthetic primers and AceQ Universal SYBR qPCR Master Mix (TaKaRa, Dalian, China). Cycle time values were measured. The following 2-stage program provided by the manufacturer was used as follows: $5 \mathrm{~min}$ at $95^{\circ} \mathrm{C}, 15 \mathrm{~s}$ at $60^{\circ} \mathrm{C}$, and then 40 cycles of $10 \mathrm{~s}$ at $95^{\circ} \mathrm{C}$ and $30 \mathrm{~s}$ at $60^{\circ} \mathrm{C}$. Each sample was tested in triplicate, and the analyses of the relative gene protocol expression data using the $2^{-\Delta \Delta c t}$ method were performed [21]. The sequences of the primer pairs is presented in Table I.

\section{Enzyme-linked immunosorbent assay (ELISA)}

BV2 cells were inoculated into 24-well plates at a density of $5 \times 10^{4}$ cells $/ \mathrm{ml}$. After the cells were adhered to the wall and treatments with different experiments were performed, lysates were centrifuged at $12,000 \mathrm{rpm}$ for 20 mins at $4^{\circ} \mathrm{C}$, and the level of IL-1 $\beta$, TNF- $\alpha$ and IL- 6 in the cells was measured using ELISA kit (MyBioSource, CA, USA).

\section{Western blotting analysis}

An ultrasonic cell crusher was used to crack the cells, and Eppendorf centrifuge was used to centrifuge

Table I. The sequences of primers in the RT-qPCR assay

\begin{tabular}{|lcc|}
\hline Genes & Forward $\left(5^{\prime}-3^{\prime}\right)$ & Reverse $\left(5^{\prime}-3^{\prime}\right)$ \\
\hline HMGB1 & GAAGAGGAGGAAGAAGAGGA & GCAAGGTTAGTGGCTATTGA \\
\hline RAGE & TGAGGCCAAATCGTGGGACATGT & GTTCAAATGTGACCAATTTG \\
\hline TLR2 & CAGTGGCAACGCTATAGTTCTC & GTGATAGGTGGTGCACAGATAG \\
\hline TLR4 & GTAAAGCTAAGCGGCCTAAT & AGGGCCCTATTGGCGTTAAGC \\
\hline GAPDH & AGAACATCATCCCTGCATCC & CACATTGGGGGTAGGAACAC \\
\hline
\end{tabular}


the lysates at $12,000 \mathrm{rpm}$ for 20 mins at $4^{\circ} \mathrm{C}$. Protein concentrations were measured using the BCA Protein Assay Kit (Beyotime, Shanghai, China). Samples (40 $\mu \mathrm{g}$ per lane) were separated via sodium dodecyl sulfate polyacrylamide gel electrophoresis (SDS-PAGE) and electro transferred to a polyvinylidene difluoride membrane (Millipore, CA, USA). The membrane was blocked using $5 \%$ bovine serum albumin for $1 \mathrm{~h}$ at $37^{\circ} \mathrm{C}$ and incubated overnight at $4^{\circ} \mathrm{C}$ with primary antibodies. The following antibodies were used: HMGB1 (Cell Signaling Technology, Beverly, MA, USA), RAGE (Abcam, CA, USA), TLR2 (Proteintech, Wuhan, China) and TLR4 (Cell Signaling Technology, Beverly, MA, USA). Glyceraldehyde-3-phosphate dehydrogenase (GAPDH, Goodhere Biotechnology, Hangzhou, China) was used as an internal reference. The membrane was washed three times for 5 mins in tris-buffered saline (TBS) + Tween 20 and incubated with the appropriate horseradish peroxidase-conjugated secondary antibody (Beyotime, Shanghai, China) for $1 \mathrm{~h}$ at $37^{\circ} \mathrm{C}$. Densitometry analysis was performed using the ChemiDoc detection system and Quantity One software (Bio-Rad, CA, USA).

\section{Immunofluorescence assay}

Briefly, immunofluorescence staining was carried out to analyse the distribution of HMGB1 protein in the treated BV2 cells. Microwave ovens were used for antigen retrieval in a citrate solution for 20 mins. Endogenous peroxidase activity was blocked using $3 \%$ hydrogen peroxide for 15 mins and rinsed in PBS. The glass slides that had crawled cells dripped with

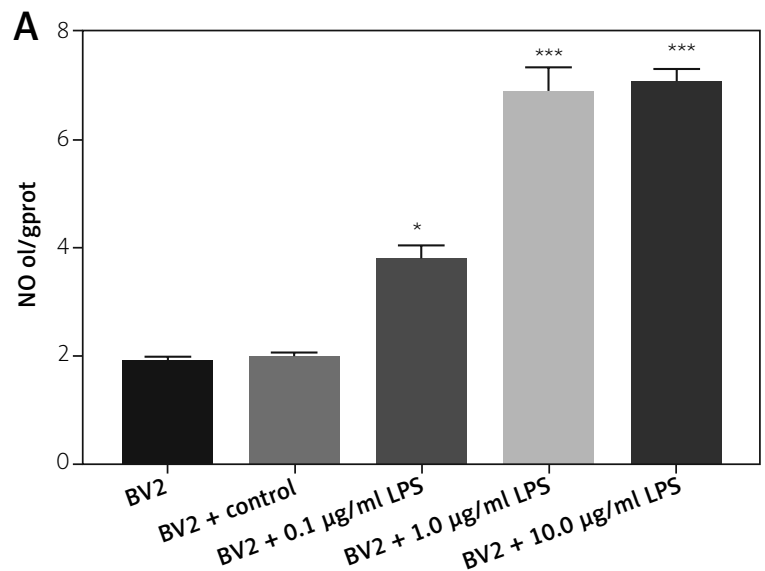

the sealing solution ( $5 \%$ donkey serum, Solarbio Science and Technology Co., Ltd., Beijing, China) at room temperature for 30 mins. Each slide was dripped with a sufficient amount of diluted antibody and put into a wet box, incubated at $4^{\circ} \mathrm{C}$ for the secondary antibodies (1 : 200, Proteintech, Wuhan, China) for $1 \mathrm{~h}$ at room temperature. Cell nuclei were stained with 4',6-diamidino-2-phenylindole (DAPI; Sigma-Aldrich, CA, USA). Fluorescence images were captured using a fluorescence microscope system (Leica, Germany).

\section{Statistical analysis}

GraphPad Prism 6.0 software was used for the statistical analyses. Data were represented as a mean \pm standard deviation (SD). The measurements were normally analyzed using either $t$-test or one-way analysis of variance (ANOVA). A $p$ value less than 0.05 was considered to be statistically significant.

\section{Results}

\section{Establishment of BV2 cell inflammatory injury model induced by LPS}

To establish an inflammatory cell model, BV2 cells were treated with $0.1,1.0$ and $10.0 \mu \mathrm{g} / \mathrm{ml}$ LPS for $4 \mathrm{hrs}$. The release of NO was evaluated in LPS-treated BV2 cells, and the results indicated that the level of $\mathrm{NO}$ was significantly elevated in BV2 cells treated with LPS relative to BV2 cells treated with equivalent medium (control), and the concentration of NO was gradually increased with the increase of LPS concentration $(p<0.05, p<0.001$, Fig. 1A). In order to ensure the suc-

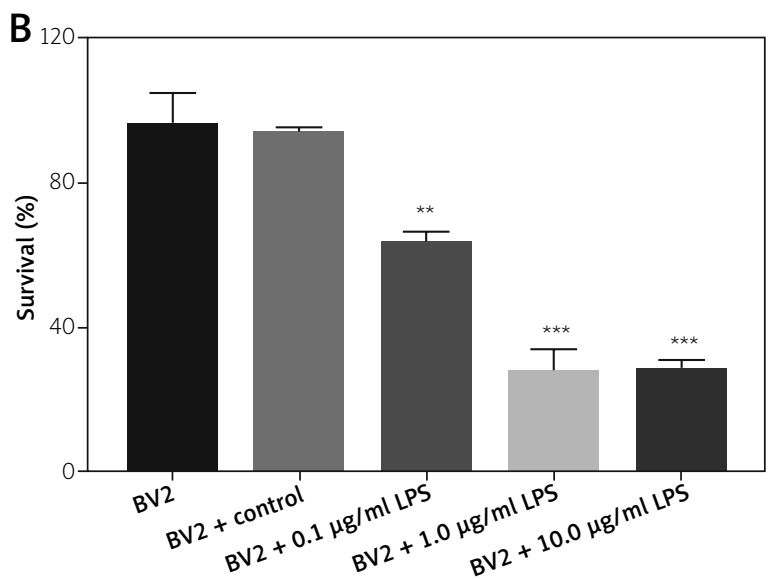

Fig. 1. Establishment of the BV2 cell inflammatory injury model induced by LPS. A) The effect of different concentrations of LPS on the release of NO from BV2 cells. B) The effects of LPS on the activity of BV2 cells. ${ }^{*} p<0.05,{ }^{* *} p<0.01,{ }^{* * *} p<0.001$ vs. control group. 

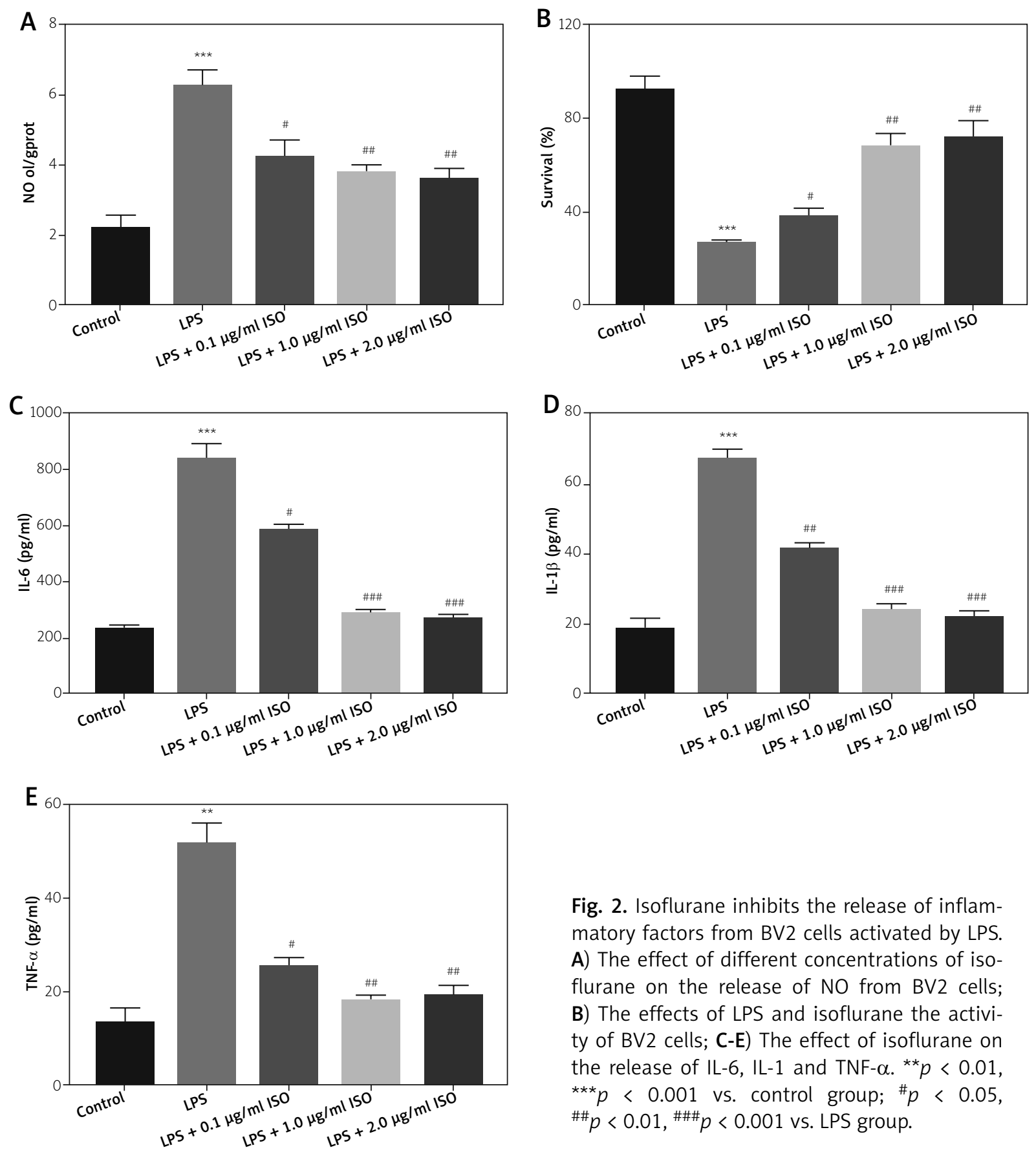

Fig. 2. Isoflurane inhibits the release of inflammatory factors from BV2 cells activated by LPS. A) The effect of different concentrations of isoflurane on the release of NO from BV2 cells; B) The effects of LPS and isoflurane the activity of BV2 cells; C-E) The effect of isoflurane on the release of IL-6, IL-1 and TNF- $\alpha .{ }^{* *} p<0.01$, ${ }^{* * *} p<0.001$ vs. control group; ${ }^{*} p<0.05$,

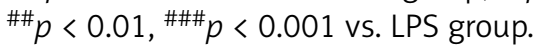

cessful modelling of the inflammatory injury model, the cell survival rate was assessed in BV2 cells after LPS treatment. The results showed that the cell survival rate was significantly reduced in LPS treatment compared to the control group ( $p<0.01, p<0.001$, Fig. 1B). In combination with a large number of literature reports, it was confirmed that BV2 cells were exposed to $1.0 \mu \mathrm{g} / \mathrm{ml}$ LPS for the follow-up experiment.

\section{Isoflurane inhibits the release of inflammatory factors from BV2 cells mediated by LPS}

To further investigate the effects of isoflurane on the LPS-induced BV2 cells, LPS-induced BV2 cells were treated with $0.1 \mu \mathrm{g} / \mathrm{ml}, 1 \mu \mathrm{g} / \mathrm{ml}$ and $2 \mu \mathrm{g} / \mathrm{ml}$ isoflurane. The release of $\mathrm{NO}$ and survival rate of 

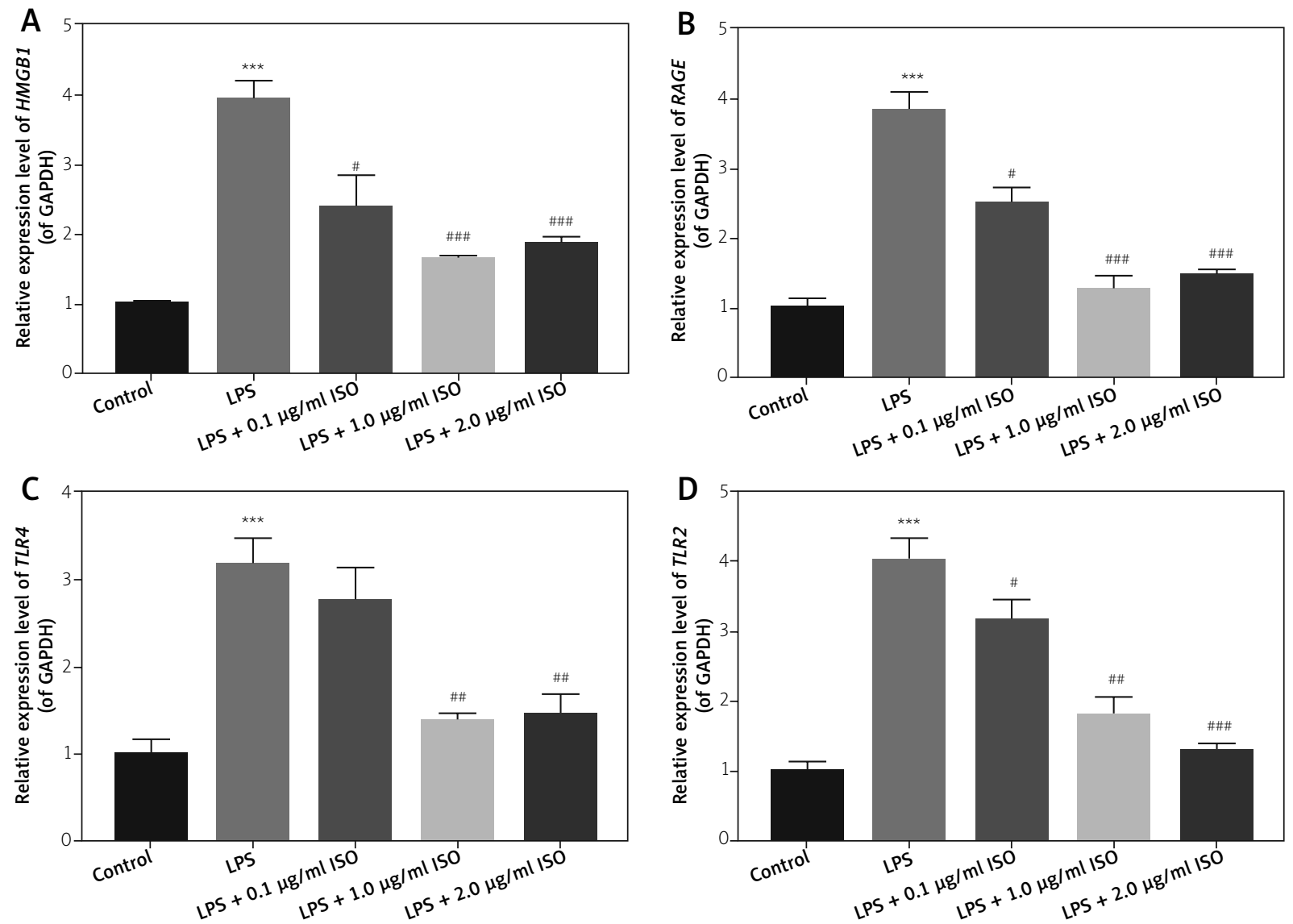

Fig. 3. Isoflurane downregulated HMGB1, RAGE, TLR4 and TLR2 expressions in LPS-mediated BV2 cells. The mRNA expression levels of HMGB1 (A), RAGE (B), TLR4 (C) and TLR2 (D) were analysed by RT-qPCR assay.

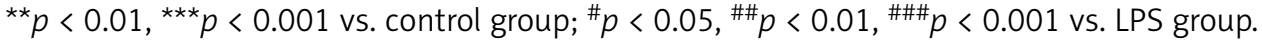

LPS-induced BV2 cells were examined after treatment with different concentrations of isoflurane. As shown in Figure 2A, the concentration of NO was markedly increased in the LPS group compared with the control group, indicating that LPS promoted the release of NO; while the increase in NO concentration could be weakened by isoflurane treatment $(p<0.05, p<0.01, p<0.001)$. Meanwhile, we proved that LPS significantly reduced the survival rate of BV2 cells, while the reduction in the survival rate of BV2 cells could be reversed by isoflurane, and as the concentration of isoflurane increases, the reversal effect gradually increased ( $p<0.05, p<0.01$, $p<0.001$, Fig. 2B). The results proved that isoflurane could protect BV2 cells in the resting state or $1.0 \mu \mathrm{g} / \mathrm{ml}$ LPS in the dose range used in this experiment. In addition, the influence of isoflurane on inflammatory factors was confirmed. The results revealed that the concentrations of IL-6, IL- $1 \beta$ and TNF- $\alpha$ were dramatically increased in the LPS group in comparison to the control group, while the levels of inflammatory factors were significantly decreased in LPS-induced BV2 cells after isoflurane treatment group compared to LPS-induced BV2 cells $(p<0.05$, $p<0.01, p<0.001$, Fig. 2C-E). Therefore, isoflurane could inhibit the inflammatory response of LPS-induced BV2 cells in a dose-effect relationship.

\section{Isoflurane downregulated HMGB1, RAGE, TLR4 and TLR2 expressions in LPS-mediated BV2 cells}

In order to confirm whether isoflurane plays an anti-inflammatory role through HMGB1/TLRs signalling pathway, RT-qPCR and western blot assays were carried out to confirm the expression changes of HMGB1, RAGE, TLR4 and TLR2 in LPS-mediated BV2 cells. Our results 

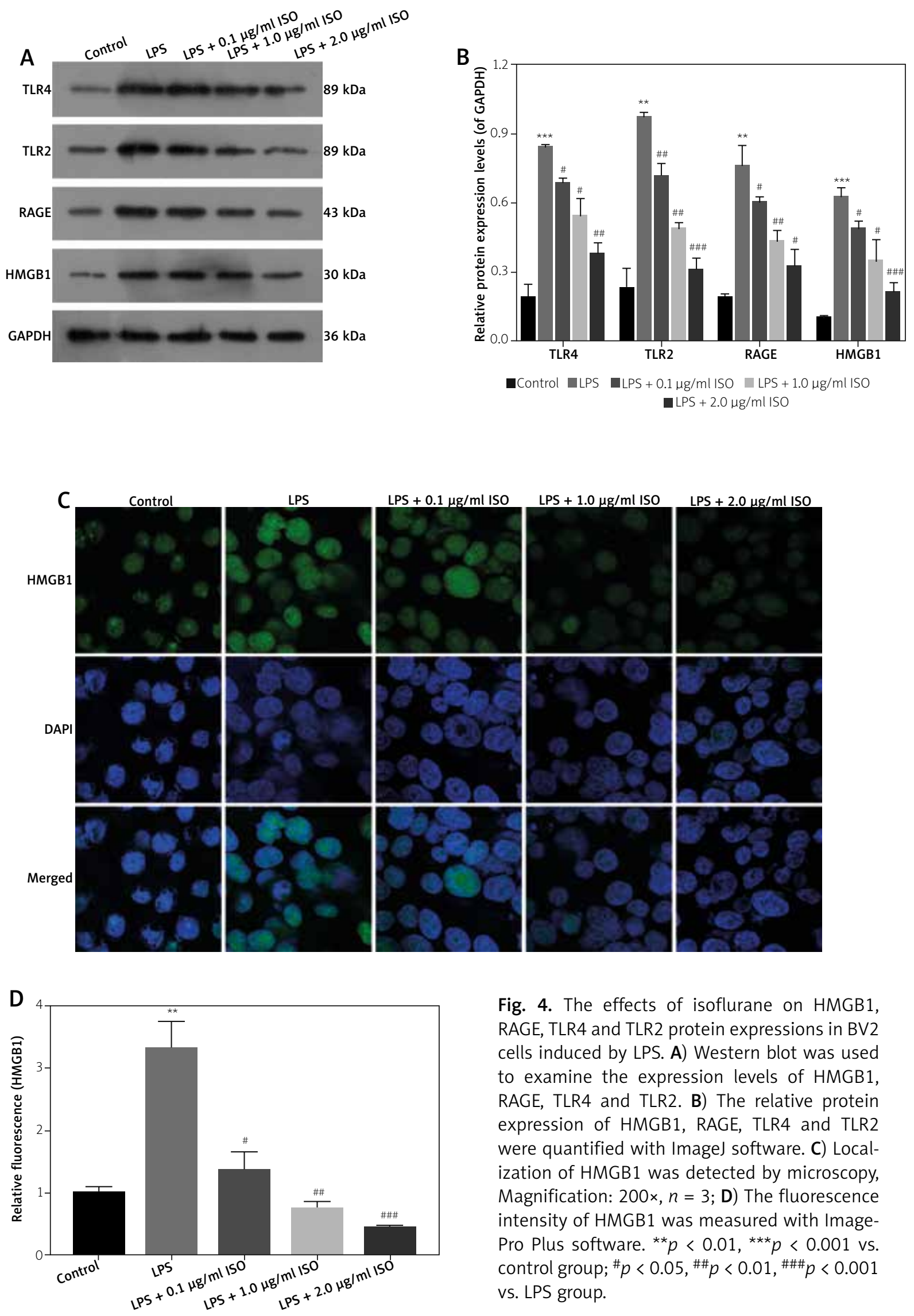

Fig. 4. The effects of isoflurane on HMGB1, RAGE, TLR4 and TLR2 protein expressions in BV2 cells induced by LPS. A) Western blot was used to examine the expression levels of HMGB1, RAGE, TLR4 and TLR2. B) The relative protein expression of HMGB1, RAGE, TLR4 and TLR2 were quantified with ImageJ software. C) Localization of HMGB1 was detected by microscopy, Magnification: 200x, $n=3$; D) The fluorescence intensity of HMGB1 was measured with ImagePro Plus software. ${ }^{* *} p<0.01,{ }^{* * *} p<0.001$ vs. control group; ${ }^{\#} p<0.05,{ }^{\# \#} p<0.01,{ }^{\# \#} p<0.001$ vs. LPS group. 

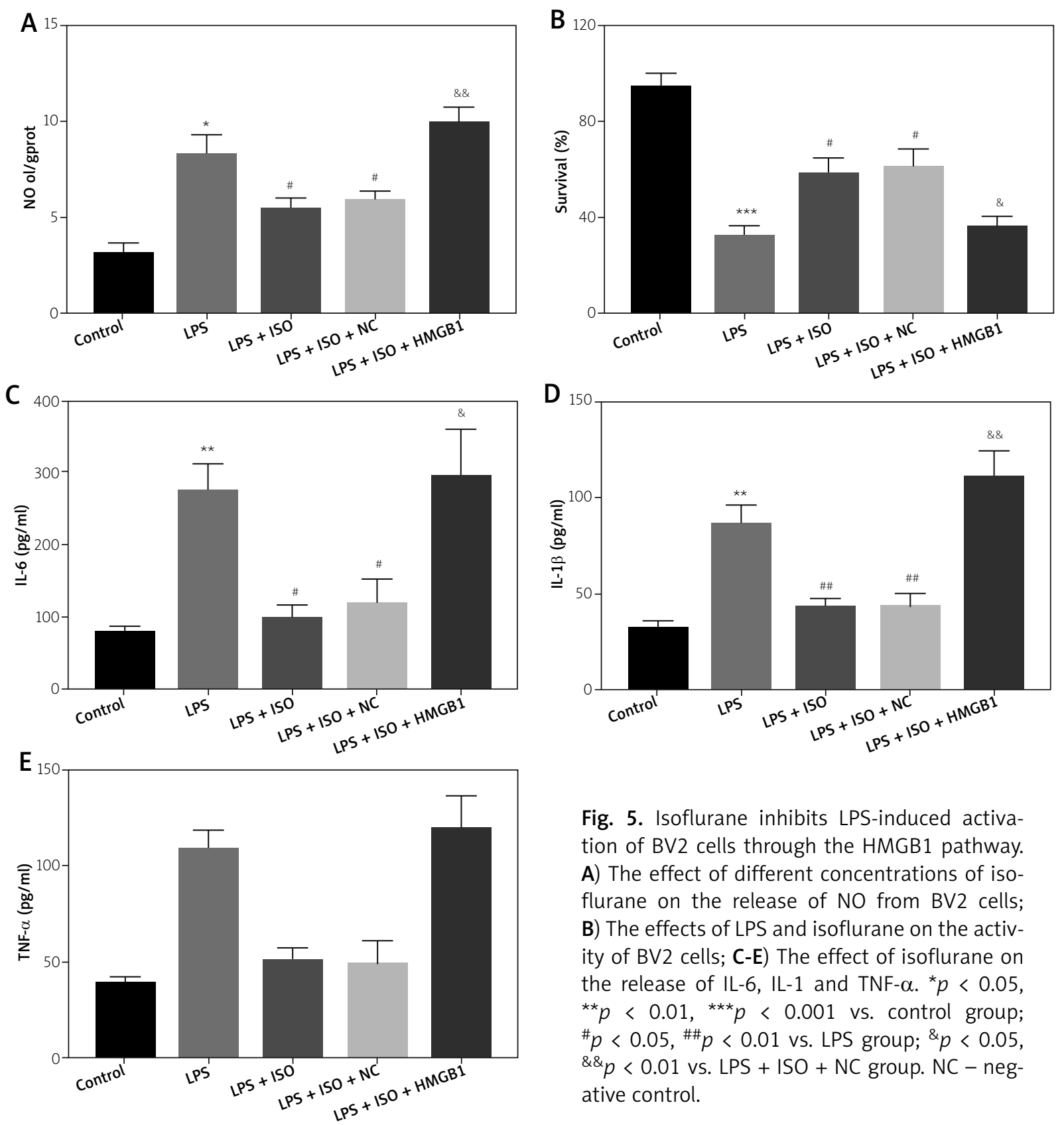

Fig. 5. Isoflurane inhibits LPS-induced activation of BV2 cells through the HMGB1 pathway. A) The effect of different concentrations of isoflurane on the release of NO from BV2 cells; B) The effects of LPS and isoflurane on the activity of BV2 cells; C-E) The effect of isoflurane on the release of IL-6, IL-1 and TNF- $\alpha$. ${ }^{*} p<0.05$, ${ }^{* *} p<0.01,{ }^{* * *} p<0.001$ vs. control group; ${ }^{\#} p<0.05, \# p<0.01$ vs. LPS group; $\& p<0.05$, $\& \& p<0.01$ vs. LPS + ISO + NC group. NC - negative control.

indicated that HMGB1, RAGE, TLR4 and TLR2 expressions were markedly upregulated in the LPS group vs. the control group, while the upregulations of HMGB1, RAGE, TLR4 and TLR2 expressions were then inhibited by isoflurane in LPS-induced BV2 cells $(p<0.05, p<0.01$, $p<0.001$, Figs. 3 and $4 A-B)$. Moreover, the results of the immunofluorescence assay further showed that isoflurane markedly suppressed HMGB1 expression in LPS-induced BV2 cells, and the level of HMGB1 expression was gradually reduced with the con-

centration increasing, besides, HMGB1 protein was mainly distributed in the nucleus $(p<0.05, p<0.01$, $p<0.001$, Fig. 4C-D).

\section{Isoflurane inhibits LPS-induced activation of BV2 cells through HMGB1 pathway}

In order to further confirm whether isoflurane plays an anti-inflammatory role through HMGB1 signalling pathway, HMGB1 overexpression adeno- 

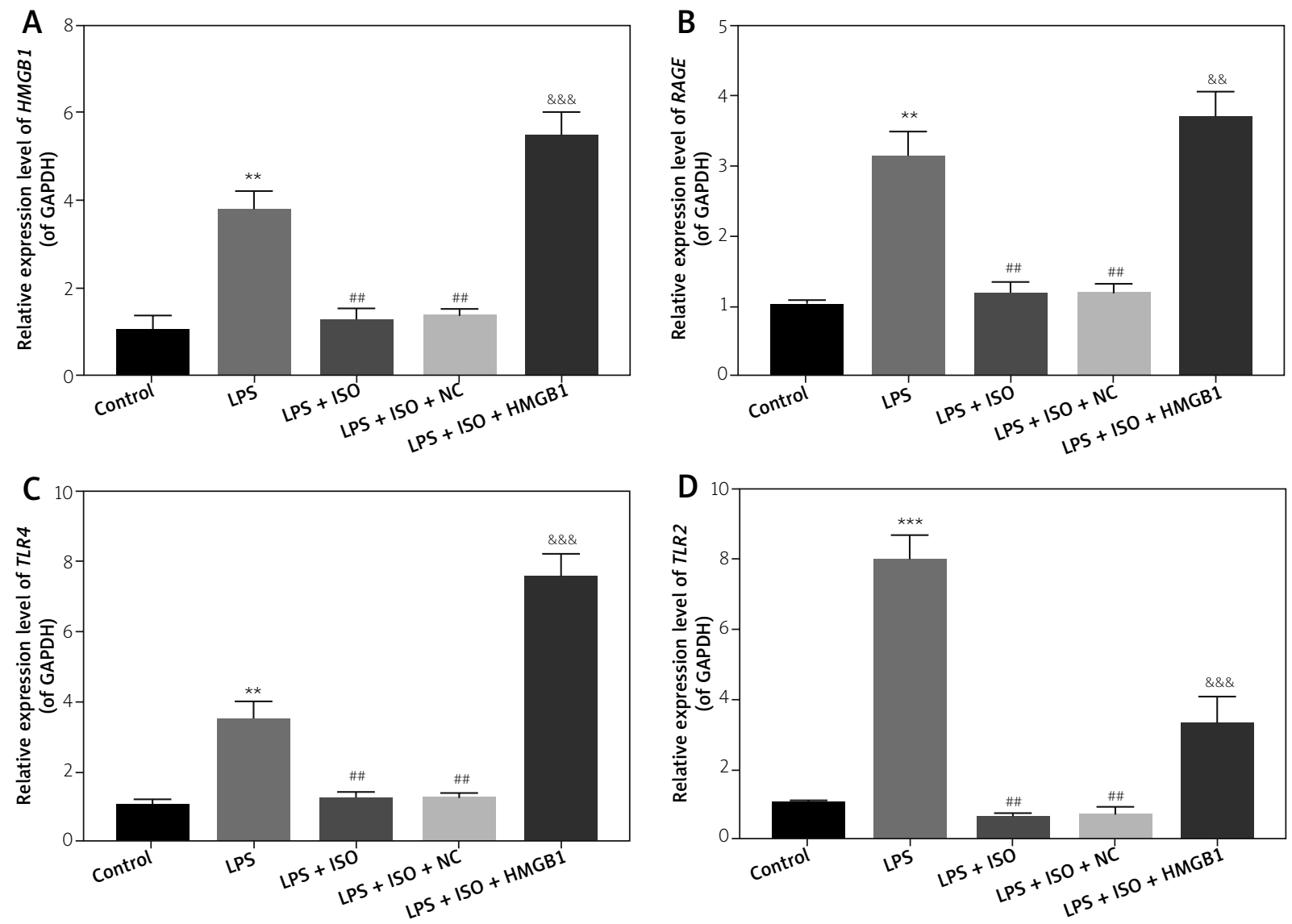

Fig. 6. Isoflurane decreased LPS-induced HMGB1, RAGE, TLR4 and TLR2 expressions in BV2 cells by HMGB1. The mRNA expression levels of HMGB1 (A), RAGE (B), TLR4 (C) and TLR2 (D) were evaluated by RT-qPCR assay in the LPS-treated BV2 cells after treatment with isoflurane and Ad-HMGB1. ${ }^{* *} p<0.01,{ }^{* * *} p<0.001$ vs. control group; ${ }^{\# \#} p<0.01$ vs. LPS group; ${ }^{\& \&} p<0.01,{ }^{\& \& \&} p<0.001$ vs. LPS + ISO + NC group. NC - negative control.

viruses were selected for transfected BV2 cells and we further explored the roles of HMGB1/TLRs signalling pathway in the inhibitory effect of isoflurane on LPS-activated neuro microglia (BV2 cells). Firstly, our results revealed that the release of NO was notably prevented by isoflurane in LPS-induced BV2 cells, while overexpression of HMGB1 observably blocked this protective effect of isoflurane and then accelerated the release of NO ( $p<0.05, p<0.01$, Fig. 5A). Secondly, we proved that overexpression of HMGB1 could reduce the survival rate, which was facilitated by isoflurane treatment in LPS-induced BV2 cells ( $p<0.05, p<0.001$, Fig. 5B). Besides, our results indicated that overexpression of HGBM1 could attenuate the inhibitory effects of isoflurane on the concentrations of TNF- $\alpha$, IL-1 $\beta$ and IL- 6 in LPS-induced
BV2 cells ( $p<0.05, p<0.01, p<0.001$, Fig. 5C-D). Moreover, our results disclosed that HMGB1, RAGE, TLR4 and TLR2 expressions, which were inhibited by isoflurane treatment in LPS-induced BV2 cells, could be significantly reversed by HMGB1 overexpression ( $p<0.05, p<0.01, p<0.001$, Figs. 6 and 7A-B).

\section{Discussion}

A large number of literature studies have confirmed that LPS activates microglia and promotes the increase in pro-inflammatory cytokines such as TNF- $\alpha, I L-1 \beta$ and IL-6. It was further found that pro-inflammatory factors combined with surface antibodies against dopaminergic neurons initiated an intracellular inflammatory cascade reaction and induced the death of dopamine neurons [20,33]. 

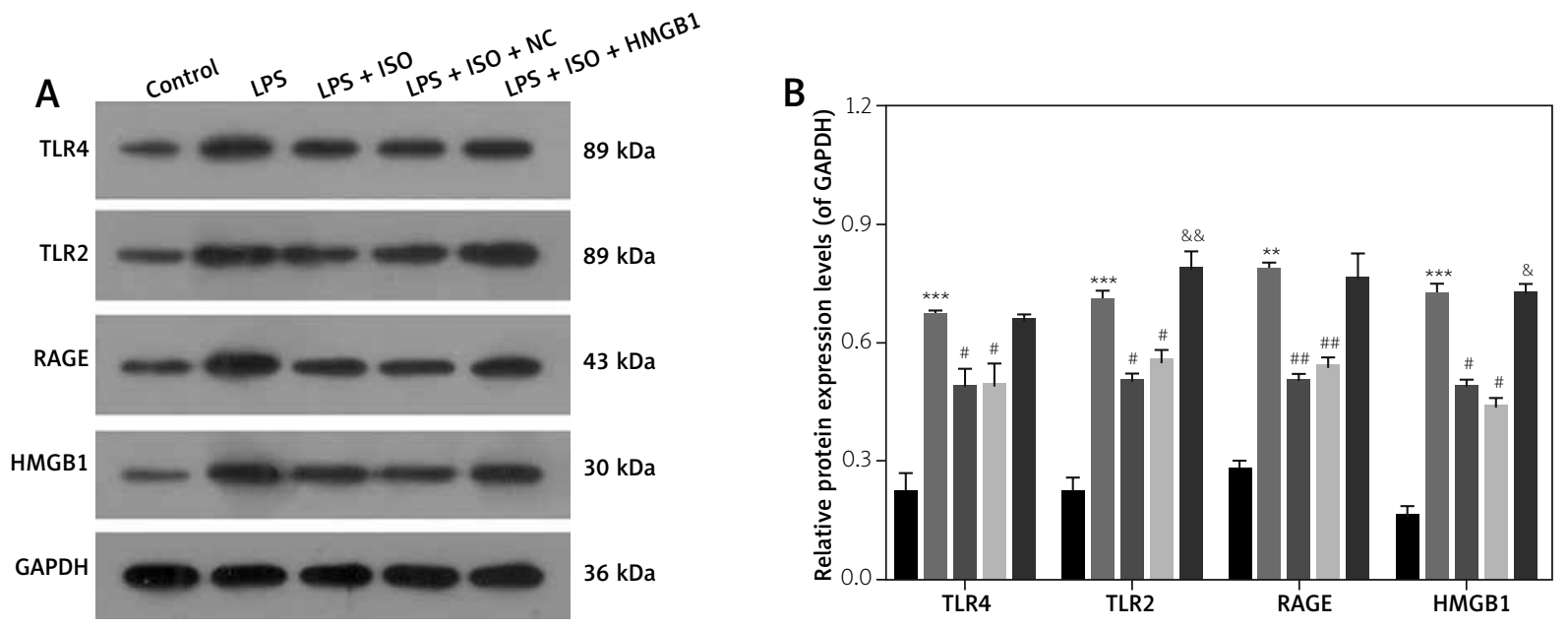

aControl $\square$ LPS $\square$ LPS + ISO $\square$ LPS + ISO + NC $\square$ LPS + ISO + NC + HMGB1
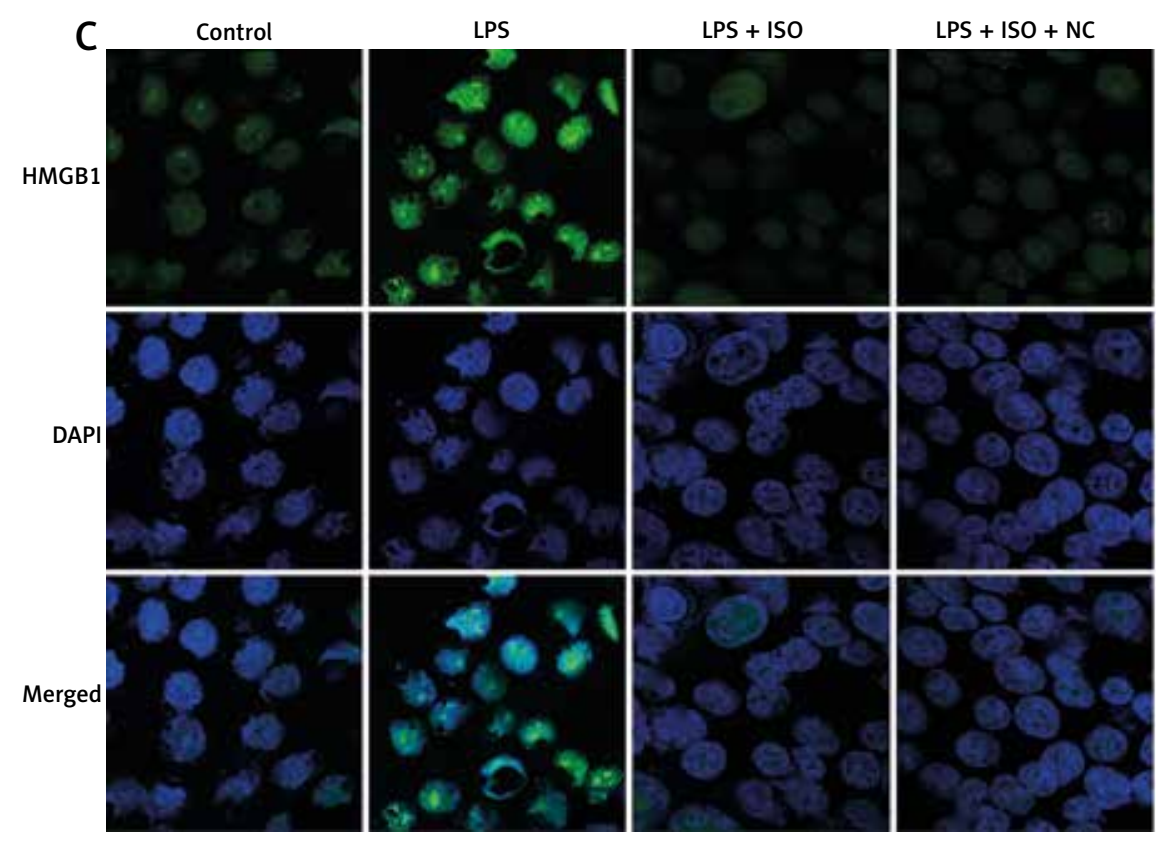

LPS + ISO + HMGB1

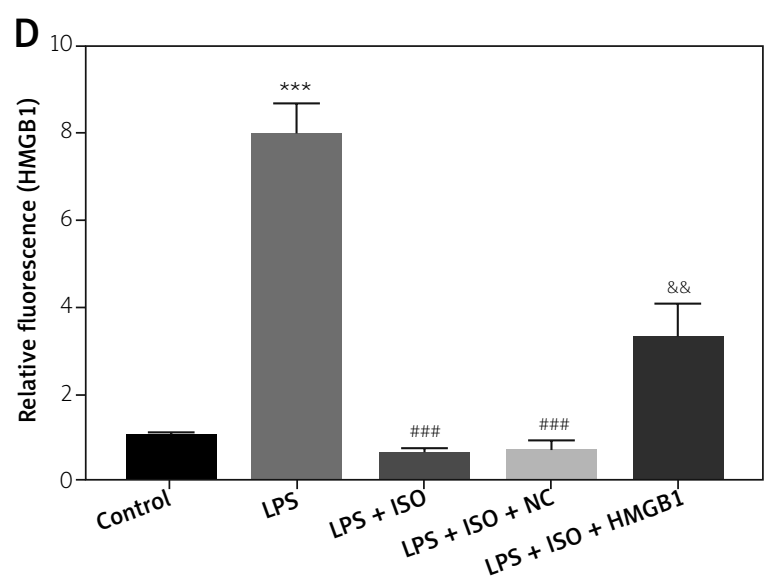

Fig. 7. Identification of HMGB1, RAGE, TLR4 and TLR2 protein expressions in LPS-treated BV2 cells after treatment with isoflurane and Ad-HMGB1. A) Western blot was carried out confirm the protein expression levels of HMGB1, RAGE, TLR4 and TLR2. B) HMGB1, RAGE, TLR4 and TLR2 expressions were quantified using ImageJ software. C) Localization of HMGB1 was assessed by microscopy, Magnification: 200x; D) The fluorescence intensity of HMGB1 was measured with Image-Pro Plus software. ${ }^{* *} p<0.01$, ${ }^{* * *} p<0.001$ vs. control group; ${ }^{\#} p<0.05$, ${ }^{* \#} p<0.01$, $\# \# p<0.001$ vs. LPS group; $\& p<0.05, \& \& p<0.01$ vs. LPS + ISO + NC group. NC - negative control. 
The serum of activated BV2 cells contains a large number of inflammatory factors, including TNF- $\alpha$, IL-1 $\beta$, and IL-6. Our study has shown that treatment with isoflurane can decrease inflammatory factors, including TNF- $\alpha$, IL- $1 \beta$, and IL- 6 . TNF- $\alpha$ is an inflammatory mediator which plays a central role in the initiation and regulation of other inflammatory toxic factors, and can induce the secretion of IL-1 $\beta$, IL-6 and other inflammatory factors [6]. The inflammatory process stimulated by IL-1 $\beta$ is usually harmful and also strengthens the damage caused by other inducers. This phenomenon may occur by directly injuring neurons or interfering with neurotrophin-mediated neuronal survival [10]. Interleukin 6 is another key member of the IL- 6 family, which can regulate immune response and participate in inflammatory processes. Moreover, when the expression of TNF- $\alpha$, IL- $1 \beta$ and IL- 6 was blocked, the severity of neurodegenerative diseases could also be improved. Therefore, inhibiting the level of inflammatory factors can slow down or even prevent the degeneration of dopaminergic neurons.

It has been confirmed that LPS induced activation of BV2 cells and released pro-inflammatory cytokines and cytotoxicity factors, such as TNF- $\alpha$, IL- 6 and IL-1 $\beta[13,20]$. BV2 cells are the most widely used microglial cell lines and can replace primary microglial cells in immune function, which have been widely used in neuroinflammation. In agreement with the previous study [5], our data showed that the TLRs pathway was activated and involved in the neuroinflammation in the early period after LPS induction. The expression of HMGB1, RAGE, and TLRs protein in BV2 cells which due to treatment by isoflurane was significantly lower than in the control group; this suggested that isoflurane may inhibit the activation of microglia through TLR4 pathway. Several reports have independently demonstrated that TLR2/4 and RAGE were involved in the inflammatory responses [9]. Therefore, it is likely that both TLR2/4 and RAGE mediate the action of HMGB1.

TLRs, a family of pattern recognition receptors, play a pivotal role in the inflammatory response. TLR4, a key member of the TLRs, is highly expressed on microglia [42]. It can be activated by endogenous ligands released from various cells, such as HMGB1. It can be seen that TLR4 plays an indispensable role in the activation of microglia. TLR4-mediated microglia activation can reduce neuroinflammatory response to a certain extent. HMGB1, as the downstream junction protein of TLR4, was similar to TLR4, which is a novel, cytokine-like, and ubiquitous, highly conserved, nuclear protein that can be actively secreted by microglia or passively released by necrotic neurons. A growing body of evidence supports the idea that HMGB1 is a cytokine that regulates inflammation and immune response [24]. In order to confirm whether isoflurane played an anti-inflammatory role mediated by the HMGB1/TLRs pathway, we selected the overexpression vector of HMGB1 to further study the role of HMGB1 in the inhibition of lipopolysaccharide-activated neuro microglia by isoflurane. In our study, LPS could promote the expression of HMGB1/TLR4 protein. However, it could significantly down-regulate the expressions of HMGB1/TLR4 proteins in the intervention of isoflurane.

Previous studies have pointed out the neurotoxicity of volatile anaesthetics including isoflurane. It is worth noting that the concentration used is high or exposure time lasts usually more than $4 \mathrm{hrs}$. Studies have shown that preconditioning neonatal rats with $1.5 \%$ isoflurane can reduce brain injury in the survivors [38]. Extracellular HMGB1 is known to induce complex cascades of signalling via binding to its receptors, including RAGE, TLR2 and TLR4. HMGB1 can trigger inflammation [22], cardiac regeneration [19], and neurite outgrowth [25].

The above results showed that isoflurane could inhibit the expression of HMGB1, RAGE, TLR2/4 protein in BV2 cells induced by LPS. Combining the research listed above, we speculated that isoflurane can inhibit the activation of neuro microglia by lipopolysaccharide, reduce the release of inflammatory factors, and protect nerve cells by regulating the expression of HMGB1 and its receptor TLR2/4.

In conclusion, we demonstrated that isoflurane might have neuroprotective effects against LPS-induced neuroinflammation in microglia cells by downregulating HMGB1/TLRs pathway, which might provide an experimental basis for the study of isoflurane as a protective factor for the prevention of neurodegenerative diseases. However, there are limitations on our current research. In the future research, we also will further explore the comprehensive functions and mechanisms of isoflurane LPS-induced BV2 cells and in vivo animal models.

\section{Acknowledgments}

This study was supported by the National Natural Science Foundation of China (no. 81471192). 


\section{Disclosure}

\section{The authors report no conflict of interest.}

\section{References}

1. Altay O, Suzuki H, Hasegawa Y, Ostrowski RP, Tang J, Zhang JH. Isoflurane on brain inflammation. Neurobiol Dis 2014; 62: 365-371.

2. Ball C, Westhorpe RN. Isoflurane. Anaesth Intensive Care 2007; 35: 467.

3. Colonna M, Butovsky O. Microglia function in the central nervous system during health and neurodegeneration. Annu Rev Immunol 2017; 35: 441-468.

4. Dec K, Łukomska A, Maciejewska D, Jakubczyk K, BaranowskaBosiacka I, Chlubek D, Wąsik A, Gutowska I. The influence of fluorine on the disturbances of homeostasis in the central nervous system. Biol Trace Elem Res 2017; 177: 224-234.

5. Ding RR, Chen W, Guo CY, Liao WT, Yang X, Liao FE, Lin JM, Mei $H F$, Zeng Y. Dangguishaoyao-San attenuates LPS-induced neuroinflammation via the TLRs/NF-kappaB signaling pathway. Biomed Pharmacother 2018; 105: 187-194.

6. Foreman B. The pathophysiology of delayed cerebral ischemia J Clin Neurophysiol 2016; 33: 174-182.

7. Fu R, Shen Q, Xu P, Luo JJ, Tang Y. Phagocytosis of microglia in the central nervous system diseases. Mol Neurobiol 2014; 49: 14221434.

8. Gaidhani N, Sun F, Schreihofer D, Uteshev VV. Duration of isoflurane-based surgical anesthesia determines severity of brain injury and neurological deficits after a transient focal ischemia in young adult rats. Brain Res Bull 2017; 134: 168-176.

9. Gąsiorowski K, Brokos B, Echeverria V, Barreto GE, Leszek J. RAGETLR crosstalk sustains chronic inflammation in neurodegeneration. Mol Neurobiol 2017; 55: 1-14.

10. Gougeon PY, Lourenssen S, Han TY, Nair DG, Ropeleski MJ, Blennerhassett MG. The pro-inflammatory cytokines IL-1 $\beta$ and TNF $\alpha$ are neurotrophic for enteric neurons. J Neurosci. 2013; 33: 3339-3351.

11. Guillemot-Legris O, Masquelier J, Everard A, Cani PD, Alhouayek M, Muccioli GG. High-fat diet feeding differentially affects the development of inflammation in the central nervous system. J Neuroinflammation 2016; 13: 206.

12. Homi HM, Mixco J, Sheng TH, Grocott HP, Pearlstein RD, Warner DS. Severe hypotension is not essential for isoflurane neuroprotection against forebrain ischemia in mice. Anesthesiology 2003; 99: 1145-1151.

13. Hu X, Zhou H, Zhang D, Yang S, Qian L, Wu HM, Chen PS, Wilson B, Gao HM, Lu RB. Clozapine protects dopaminergic neurons from inflammation-induced damage by inhibiting microglial overactivation. J Neuroimmune Pharmacol 2012; 7: 187-201.

14. Huang Y, Wang XX, Sun DD, Zhang ZX, Yang WW, Shao T, Han H, Zhang EF, Pu ZS, Hou ZX, Dong HL, Xiong LZ, Hou LC. Sub-anesthesia dose of isoflurane in $60 \%$ oxygen reduces inflammatory responses in experimental sepsis models. Chin Med J (Engl) 2017; 130: 840-853

15. Kabba JA, Xu Y, Christian H, Ruan W, Chenai K, Xiang Y, Zhang L, Saavedra JM, Pang T. Microglia: housekeeper of the central nervous system. Cell Mol Neurobiol 2017; 38: 1-19.
16. Kozlova AL, Valieva ME, Maluchenko NV, Studitsky VM. HMGB proteins as DNA chaperones that modulate chromatin activity. Mol Biol 2018; 52: 737-749.

17. Lewerenz J, Ates G, Methner A, Conrad M, Maher P. Oxytosis/ ferroptosis-(Re-) emerging roles for oxidative stress-dependent non-apoptotic cell death in diseases of the central nervous system. Front Neurosci 2018; 12: 214.

18. Li L, Li Z, Cao Y, Fan D, Chui D, Guo X. Increased extrasynaptic GluN2B expression is involved in cognitive impairment after isoflurane anesthesia. Exp Ther Med 2016; 12: 161-168.

19. Limana F, Germani A, Zacheo A, Kajstura J, Di Carlo A, Borsellino G, Leoni O, Palumbo R, Battistini L, Rastaldo R, Müller S, Pompilio G, Anversa P, Bianchi ME, Capogrossi MC. Exogenous high-mobility group box 1 protein induces myocardial regeneration after infarction via enhanced cardiac C-kit+ cell proliferation and differentiation. Circ Res 2005; 97: e73-83.

20. Liu Y, Chen HL, Yang G. Extract of tripterygium wilfordii hook F protect dopaminergic neurons against lipopolysaccharide-induced inflammatory damage. Am J Chin Med 2010; 38: 801-814.

21. Livak KJ, Schmittgen TD. Analysis of relative gene expression data using real-time quantitative PCR and the 2(-Delta Delta C(T)) method. Methods 2001; 25: 402-408

22. Lotze MT, Tracey KJ. High-mobility group box 1 protein (HMGB1): nuclear weapon in the immune arsenal. Nat Rev Immunol 2005; 5: 331-342.

23. Matchett GA, Allard M, Martin R, Zhang JH. Neuroprotective effect of volatile anesthetic agents: molecular mechanisms. Neurol Res 2009; 31: 128-134.

24. Martinotti S, Patrone M, Ranzato E. Emerging roles of HMGB1 protein in immunity, inflammation and cancer. Immunotargets Ther 2015; 4: 101-109.

25. Merenmies J, Pihlaskari R, Laitinen J, Wartiovaara J, Rauvala $\mathrm{H}$. 30-kDa heparin-binding protein of brain (amphoterin) involved in neurite outgrowth. Amino acid sequence and localization in the filopodia of the advancing plasma membrane. J Biol Chem 1991; 266: 16722-16729.

26. Naglova H, Bucova M. HMGB1 and its physiological and pathological roles. Bratisl Lek Listy 2012; 113: 163-171.

27. Ng KT, Alston RP, Just G, McKenzie C. Assessing the depth of isoflurane anaesthesia during cardiopulmonary bypass. Perfusion 2018; 33: 148-155.

28. Ohta K, Graf R, Rosner G, Heiss WD. Profiles of transient cortical depolarization and calcium ion influx in periinfarct regions of focal cerebral ischemia in cats. Ischemic Blood Flow in the Brain Book Series 2001; 6: 351-355.

29. Qiu J, Xu J, Zheng Y, Wei Y, Zhu X, Lo EH, Moskowitz MA, Sims JR. High-mobility group box 1 promotes metalloproteinase-9 upregulation through Toll-like receptor 4 after cerebral ischemia. Stroke 2010; 41: 2077-2082.

30. Reeves R. High mobility group (HMG) proteins: Modulators of chromatin structure and DNA repair in mammalian cells. DNA Repair (Amst) 2015; 36: 122-136.

31. Sayed S, Idriss NK, Sayyedf HG, Ashry AA, Rafatt DM, Mohamed AO, Blann AD. Effects of propofol and isoflurane on haemodynamics and the inflammatory response in cardiopulmonary bypass surgery. Br J Biomed Sci 2015; 72: 93-101. 
32. Schifilliti D, Grasso G, Conti A, Fodale V. Anaesthetic-related neuroprotection: intravenous or inhalational agents? CNS Drugs 2010; 24: 893-907.

33. Shen W, Qi R, Zhang J, Wang Z, Wang H, Hu C, Zhao Y, Bie M, Wang Y, Fu Y. Chlorogenic acid inhibits LPS-induced microglial activation and improves survival of dopaminergic neurons. Brain Res Bull 2012; 88: 487-494.

34. Sims GP, Rowe DC, Rietdijk ST, Herbst R, Coyle AJ. HMGB1 and RAGE in inflammation and cancer. Annu Rev Immunol 2010; 28: 367-388.

35. Sprenkle NT, Sims SG, Sánchez CL, Meares GP. Endoplasmic reticulum stress and inflammation in the central nervous system. Mol Neurodegener 2017; 12: 42.

36. Taniguchi N, Kawakami Y, Maruyama I, Lotz M. HMGB proteins and arthritis. Human Cell 2017; 31: 1-9.

37. Wang W, Chen X, Zhang J, Zhao Y, Li S, Tan L, Gao J, Fang X, Luo A. Glycyrrhizin attenuates isoflurane-induced cognitive deficits in neonatal rats via its anti-inflammatory activity. Neurosci 2016; 316: 328-336

38. Wu B, Yu Z, You S, Zheng Y, Liu J, Gao Y, Lin H, Lian Q. Physiological disturbance may contribute to neurodegeneration induced by isoflurane or sevoflurane in 14 day old rats. PLoS One 2014; 9: e84622.

39. Xiang HF, Cao DH, Yang YQ, Wang HQ, Zhu L, Ruan BH, Du J, Wang MC. Isoflurane protects against injury caused by deprivation of oxygen and glucose in microglia through regulation of the Toll-like receptor 4 pathway. J Mol Neurosci 2014; 54: 664-670.

40. Xie M, Zhang G, Yin W, Hei XX, Liu T. Cognitive enhancing and antioxidant effects of tetrahydroxystilbene glucoside in $A \beta 1-42$ induced neurodegeneration in mice. J Integr )Neurosci 2018; 17: 355-365.

41. Yang S, Liu J, Zhang X, Tian J, Zuo Z, Liu J, Yue X. Anesthetic isoflurane attenuates activated microglial cytokine-induced VSC4. 1 motoneuronal apoptosis. Am I TransI Res 2016; 8: 1437-1446.

42. Yang Y, Li S, Yang O, Shi Y, Zheng M, Liu Y, Chen F, Song G, Xu H, Wan T. Resveratrol reduces the proinflammatory effects and lipopolysaccharide-induced expression of HMGB1 and TLR4 in RAW264.7 cells. Cell Physiol Biochem 2014; 33: 1283-1292. 